\title{
Phenotypic characteristics and prognosis of inpatients with COVID-19 and diabetes: the CORONADO study
}

\author{
Bertrand Cariou ${ }^{1}$ (D) Samy Hadjadj ${ }^{1}$ (D) $\cdot$ Matthieu Wargny ${ }^{1,2}$ (D) $\cdot$ Matthieu Pichelin $^{1}$ (D) $\cdot$ Abdallah Al-Salameh $^{3}$ (D) \\ Ingrid Allix ${ }^{4}$. Coralie Amadou ${ }^{5}$ (D) $\cdot$ Gwénaëlle Arnault $^{6}$. Florence Baudoux ${ }^{7}$ - Bernard Bauduceau ${ }^{8,9}$. \\ Sophie Borot ${ }^{10}$ (D) Muriel Bourgeon-Ghittori ${ }^{11}$. Olivier Bourron ${ }^{12}$ (D) - David Boutoille ${ }^{13}$ (D) . \\ France Cazenave-Roblot ${ }^{14,15}$ (D) $\cdot$ Claude Chaumeil $^{16} \cdot$ Emmanuel Cosson $^{17,18}$ (D) Sandrine Coudol $^{2}$. \\ Patrice Darmon $^{19}$ (D) Emmanuel Disse ${ }^{20}$ (D) Amélie Ducet-Boiffard ${ }^{21}$ - Bénédicte Gaborit ${ }^{22}$ (D) Michael Joubert ${ }^{23}$ (D) \\ Véronique Kerlan ${ }^{24} \cdot$ Bruno Laviolle $^{25}$ (D) - Lucien Marchand ${ }^{26}$ (D) Laurent Meyer $^{27}$ (D) Louis Potier ${ }^{28}$ (D)

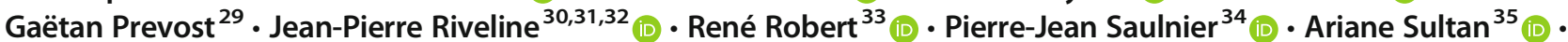 \\ Jean-François Thébaut ${ }^{16}$ (D) Charles Thivolet $^{36,37}$ (D) Blandine Tramunt $^{38} \cdot$ Camille Vatier $^{39,40}$ (D) $\cdot$ Ronan Roussel $^{28}$ (D) \\ Jean-François Gautier ${ }^{30,32}$ (D) $\cdot$ Pierre Gourdy $^{38}$ (D) for the CORONADO investigators
}

Received: 23 April 2020 / Accepted: 7 May 2020 / Published online: 29 May 2020

(C) The Author(s) 2020, corrected publication 2021

\begin{abstract}
Aims/hypothesis Coronavirus disease-2019 (COVID-19) is a life-threatening infection caused by the severe acute respiratory syndrome coronavirus-2 (SARS-CoV-2) virus. Diabetes has rapidly emerged as a major comorbidity for COVID-19 severity. However, the phenotypic characteristics of diabetes in COVID-19 patients are unknown.

Methods We conducted a nationwide multicentre observational study in people with diabetes hospitalised for COVID-19 in 53 French centres in the period 10-31 March 2020. The primary outcome combined tracheal intubation for mechanical ventilation and/or death within 7 days of admission. Age- and sex-adjusted multivariable logistic regressions were performed to assess the prognostic value of clinical and biological features with the endpoint. ORs are reported for a 1 SD increase after standardisation. Results The current analysis focused on 1317 participants: $64.9 \%$ men, mean age $69.8 \pm 13.0$ years, median BMI 28.4 (25th75 th percentile: $25.0-32.7) \mathrm{kg} / \mathrm{m}^{2}$; with a predominance of type 2 diabetes $(88.5 \%)$. Microvascular and macrovascular diabetic complications were found in $46.8 \%$ and $40.8 \%$ of cases, respectively. The primary outcome was encountered in $29.0 \%(95 \% \mathrm{CI}$ $26.6,31.5)$ of participants, while $10.6 \%(9.0,12.4)$ died and $18.0 \%(16.0,20.2)$ were discharged on day 7 . In univariate analysis, characteristics prior to admission significantly associated with the primary outcome were sex, BMI and previous treatment with renin-angiotensin-aldosterone system (RAAS) blockers, but not age, type of diabetes, $\mathrm{HbA}_{1 \mathrm{c}}$, diabetic complications or glucoselowering therapies. In multivariable analyses with covariates prior to admission, only BMI remained positively associated with the primary outcome (OR 1.28 [1.10, 1.47]). On admission, dyspnoea (OR 2.10 [1.31, 3.35]), as well as lymphocyte count (OR
\end{abstract}

A complete list of the CORONADO trial investigators is provided in the Electronic supplementary material (ESM).

Bertrand Cariou, Samy Hadjadj and Matthieu Wargny contributed equally to this article.

Electronic supplementary material The online version of this article (https://doi.org/10.1007/s00125-020-05180-x) contains peer-reviewed but unedited supplementary material, which is available to authorised users.

Bertrand Cariou

bertrand.cariou@univ-nantes.fr

Samy Hadjadj

samy.hadjadj@univ-nantes.fr

Extended author information available on the last page of the article 


\section{Research in context}

\section{What is already known about this subject?}

- Diabetes is a frequent comorbidity, as well as being a risk factor for poor prognosis, in people with COVID-19

What is the key question?

- What is the precise diabetes-related phenotype associated with COVID-19 severity in people with diabetes hospitalised for COVID-19?

\section{What are the new findings?}

- In people with diabetes hospitalised for COVID-19, the primary outcome (death or tracheal intubation for assisted mechanical ventilation within 7 days of admission) occurred in $29.0 \%$ and death (on day 7 ) in $10.6 \%$, while discharge was possible in $18.0 \%$

- BMI was independently associated with the severity of COVID-19 (primary outcome in the first 7 days following hospital admission) in a multivariable analysis

- $\quad$ Neither long-term glycaemic control (assessed by $\mathrm{HbA}_{1 c}$ measurement), nor routine therapies (including RAAS blockers and DPP-4 inhibitors), were associated with COVID-19 severity

- Age, microvascular and macrovascular diabetic complications, treated obstructive sleep apnoea, dyspnoea and some biological variables (increased AST and CRP and decreased eGFR and platelet count on admission) were independently associated with the risk of early death in people with diabetes hospitalised for COVID-19

\section{How might this impact on clinical practice in the foreseeable future?}

- Special attention should be paid to elderly people with long-standing diabetes and advanced diabetic complications, who are at increased risk of fatal COVID-19 and therefore require the strict application of specific management to avoid contamination with SARS-CoV-2. Increased BMI (starting in the overweight ranges) was an independent prognostic factor for COVID-19 severity, and the link between obesity and COVID-19 deserves further investigation

$0.67[0.50,0.88])$, C-reactive protein (OR $1.93[1.43,2.59])$ and AST (OR $2.23[1.70,2.93])$ levels were independent predictors of the primary outcome. Finally, age (OR 2.48 [1.74, 3.53]), treated obstructive sleep apnoea (OR 2.80 [1.46, 5.38]), and microvascular (OR 2.14 [1.16, 3.94]) and macrovascular complications (OR 2.54 [1.44, 4.50]) were independently associated with the risk of death on day 7.

Conclusions/interpretations In people with diabetes hospitalised for COVID-19, BMI, but not long-term glucose control, was positively and independently associated with tracheal intubation and/or death within 7 days.

Trial registration clinicaltrials.gov NCT04324736.

Keywords BMI $\cdot$ COVID-19 $\cdot$ Death $\cdot$ Diabetes $\cdot \mathrm{HbA}_{1 \mathrm{c}} \cdot$ Hypertension $\cdot$ Mechanical ventilation

\begin{tabular}{|c|c|c|c|}
\hline & DPP-4 & Dipeptidyl peptidase 4 \\
\hline \multicolumn{2}{|l|}{$\begin{array}{l}\text { Abbreviations } \\
\text { ALT }\end{array}$} & ICU & Intensive care unit \\
\hline $\mathrm{ARB}$ & Angiotensin II receptor blocker & MERS-CoV & Middle East respiratory syndrome-related \\
\hline AST & Aspartate aminotransferase & & coronavirus \\
\hline \multirow[t]{2}{*}{ CKD-EPI } & Chronic Kidney Disease Epidemiology & MRA & Mineralocorticoid-receptor antagonist \\
\hline & Collaboration & OSA & Obstructive sleep apnoea \\
\hline \multirow[t]{2}{*}{ CORONADO } & Coronavirus SARS-CoV-2 and Diabetes & RAAS & Renin-angiotensin-aldosterone system \\
\hline & Outcomes & SARS-CoV-2 & Severe acute respiratory syndrome coronavi- \\
\hline COVID-19 & Coronavirus disease-2019 & & rus- 2 \\
\hline CPK & Creatine phosphokinase & & \\
\hline CRP & C-reactive protein & & \\
\hline CT & Computed tomography & & \\
\hline
\end{tabular}




\section{Introduction}

Since the first case in China in December 2019, the epidemic of coronavirus disease-2019 (COVID-19), a disease caused by the severe acute respiratory syndrome-coronavirus-2 (SARS-CoV2) virus, rapidly spread worldwide and was declared a pandemic by the World Health Organization on 11 March $2020[1,2]$.

It is well known that people with diabetes have increased infection risk, especially for influenza and pneumonia [3, 4]. Moreover, diabetes was previously reported as a major risk factor for mortality in people infected with the 2009 H1N1 pandemic influenza and, more recently, with the Middle East respiratory syndrome-related coronavirus (MERS-CoV) $[5$, 6]. Epidemiological studies have quickly and consistently pointed out diabetes as one of the major comorbidities associated with COVID-19 and affecting its severity.

The prevalence of diabetes in patients with COVID-19 was first reported to range from 5\% to $20 \%$ in Chinese studies, increasing with the severity of the disease [7]. More recently, Grasselli et al have reported a diabetes prevalence of $17 \%$ in patients admitted to intensive care units (ICUs) for severe COVID-19 infection in Lombardy, Italy [8]. Furthermore, the COVID-19-Associated Hospitalisation Surveillance Network (COVID-NET) reported a diabetes prevalence of $28.3 \%$ in hospitalised patients in the USA [9].

More importantly, all studies published so far have reported a two- to threefold higher prevalence of diabetes in patients in ICUs compared with those with less severe disease and an increased mortality in people with diabetes [10-14]. For instance, in a retrospective study from Wuhan, diabetes was present in 19\% of 191 COVID-19 inpatients but its prevalence raised to $31 \%$ in deceased people compared with $14 \%$ in those who survived [12]. A recent meta-analysis further demonstrated that diabetes was associated with a more than doubled risk for ICU admission and a more than tripled risk for death [14].

In this context, patients with diabetes have been listed as people at higher risk for severe illness from COVID-19 by several health authorities and learned medical societies [15]. However, precise data regarding diabetes characteristics in hospitalised people with COVID-19 are still lacking. Moreover, the relationship between diabetes-related phenotypes and the severity of COVID-19 remains unknown. CORONADO (Coronavirus SARS-CoV-2 and Diabetes Outcomes) is a nationwide multicentre observational study that aims to identify the clinical and biological features associated with disease severity and mortality risk in people with diabetes hospitalised for COVID-19.

\section{Methods}

Study oversight The CORONADO study was launched in all French hospitals volunteering to share data on hospitalised
COVID-19 patients with diabetes. The study was sponsored by CHU (centre hospitalier universitaire) Nantes, designed in accordance with the declaration of Helsinki and conducted in accordance with French legislation with approval obtained from the local ethics committee (Institutional Review Board/Institutional Ethics Committee - GNEDS [groupe nantais d'éthique dans le domaine de la santé]; Ref. CORONADOV2), the CEREES (comité d'expertise pour les recherches, les études et les évaluations dans le domaine de la santé; $\mathrm{n}^{\circ}$ INDS [institut national des données de santé]:1544730) and the CNIL (commission nationale de l'informatique et des libertés; DR-2020-155/920129). In light of the purely non-interventional design of this observational study and the emergency situation related to the COVID-19 pandemic, the CNIL and the GNEDS have repealed the systematic collection of written informed consent. They recommended that we collect an 'oral non-opposition to participate' as far as possible (in particular by publishing study information via posters in the hospitals). Living patients who were unable to give consent on admission all received information about their inclusion in the CORONADO study before discharge, and therefore had a clear and free choice to object to the use of their clinical data. Any patient declining to participate in the study or expressing his or her opposition to data collection from hospital information systems, even after hospital discharge, was excluded from the study.

Study design and participants The aim of the CORONADO study was to describe the phenotypic characteristics and prognosis of individuals admitted to hospital with COVID-19 between 10 March and 10 April 2020. Inclusion criteria were (1) hospitalisation in a dedicated COVID-19 unit with COVID-19 diagnosis confirmed biologically (by SARS-CoV-2 PCR test) and/or clinically/radiologically (i.e. as ground-glass opacity and/or crazy paving on chest computed tomography [CT] scan); (2) personal history of diabetes or newly diagnosed diabetes on admission (i.e. $\mathrm{HbA}_{1 \mathrm{c}} \geq 48 \mathrm{mmol} /$ mol [6.5\%] during hospitalisation).

Owing to the rapid recruitment rate and in order to make clinically relevant findings available as quickly as possible, the scientific committee, on 5 April 2020, suggested a premature database lock on 18 April 2020 for participants admitted in the period 10-31 March 2020, and continuation of recruitment with no further modification. A first set of analyses was performed in 1317 participants selected according to the following criteria: (1) meeting the eligibility criteria; (2) available information on the main outcome, recorded on day 7 following admission; (3) available data on age and sex (see flowchart in Fig. 1). 


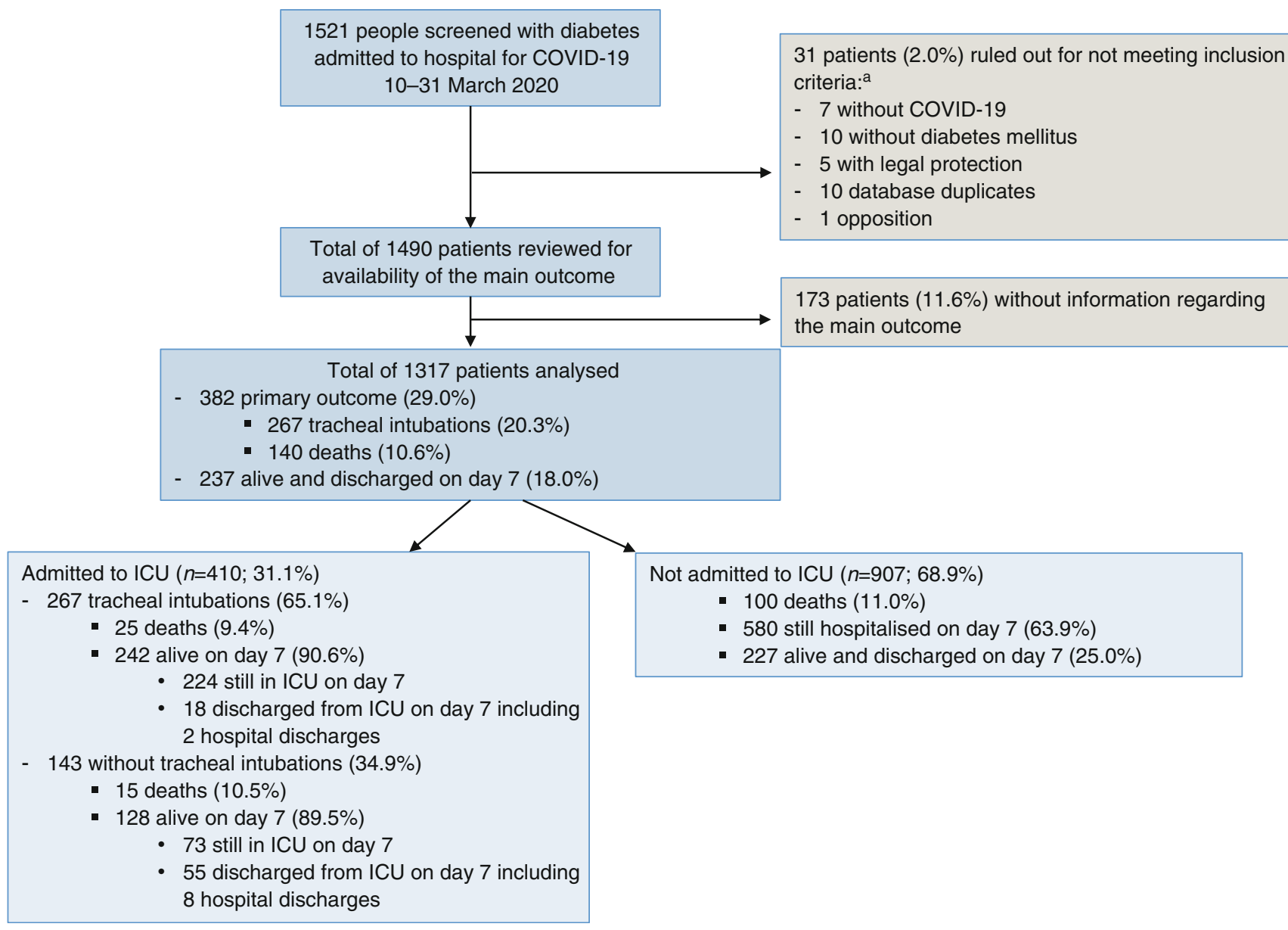

Fig. 1 Study flowchart. ${ }^{\text {a }}$ Two patients ruled out for not meeting inclusion criteria were in two categories

Patient follow-up and clinical outcomes The composite primary endpoint combined tracheal intubation for mechanical ventilation and death within 7 days of admission. Secondary outcomes included death on day 7 , tracheal intubation on day 7, admission to ICUs and discharge on day 7. Participants discharged before day 7 were systematically contacted to check for the nonoccurrence of these events on day 7 .

Data collection Data collection was performed by clinical research associates and physicians in participating centres. They were instructed to systematically review the medical files of all COVID-19 inpatients, select those with diabetes, extract data from their medical files and, if needed, contact the patient's general and/or specialist practitioners, regular pharmacist or biomedical laboratory. Collected data included clinical data (age, sex, ethnicity, BMI), classification of diabetes as noted in the medical file by the physician in charge of the patient, duration of diabetes, recent glycaemic control (i.e. two most recent $\mathrm{HbA}_{1 \mathrm{c}}$ levels determined before admission), microvascular and macrovascular complications and comorbidities. $\mathrm{HbA}_{1 \mathrm{c}}$ considered in the analysis was determined locally in the 7 days following admission or, if not available, was the result of a routine determination in the previous 6 months. Microvascular complications were defined as severe diabetic retinopathy (proliferative retinopathy and/or laser photocoagulation and/or clinically significant macular oedema requiring laser and/or intra-vitreal injections) and/or diabetic kidney disease (proteinuria [AER $\geq 300 \mathrm{mg} / 24 \mathrm{~h}$; urinary albumin/creatinine ratio $\geq 300 \mathrm{mg} / \mathrm{g}$; urinary albumin/creatinine ratio $\geq 30 \mathrm{mg} / \mathrm{mmol}$ creatinine; proteinuria $\geq 500 \mathrm{mg} / 24 \mathrm{~h}]$ and/or eGFR equal to or lower than

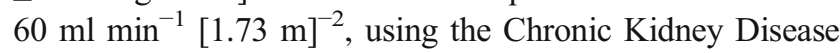
Epidemiology Collaboration [CKD-EPI] formula) and/or history of diabetic foot ulcer. Macrovascular complications were defined as ischaemic heart disease (acute coronary syndrome and/or coronary artery revascularisation) and/or cerebrovascular disease (stroke and/or transient ischaemic attack) and/or peripheral artery disease (amputation owing to ischaemic disease and/or lower limb artery revascularisation). In addition, COVID-19-related clinical, radiological and biological characteristics were collected at admission as well as their clinical evolution during the hospital stay.

Statistical analysis Quantitative data were expressed as mean \pm SD or median [25th -75 th percentile]. Categorical variables 
Table 1 Clinical characteristics prior to admission of CORONADO participants, according to primary outcome (tracheal intubation and/or death within 7 days of admission), and death on day 7

\begin{tabular}{|c|c|c|c|c|}
\hline Clinical features & $\begin{array}{l}\text { Number of people } \\
\text { with available data }\end{array}$ & All & $\begin{array}{l}\text { Primary outcome }(n=382) \\
\text { OR }(95 \% \mathrm{CI})\end{array}$ & $\begin{array}{l}\text { Death }(n=140) \\
\text { OR }(95 \% \mathrm{CI})\end{array}$ \\
\hline Sex (female/male) & 1317 & $462 / 1317(35.1)$ & $0.77(0.60,0.99)$ & $0.80(0.55,1.17)$ \\
\hline Age $(\text { years })^{\mathrm{a}}$ & 1317 & $69.8 \pm 13.0$ & $1.00(0.99,1.01)$ & $1.09(1.07,1.11)$ \\
\hline Age class (years) & 1317 & & & \\
\hline$<55$ & & $159 / 1317(12.1)$ & 1 & 1 \\
\hline $55-64$ & & 266/1317 (20.2) & $0.58(0.38,0.90)$ & $1.00(0.23,4.23)$ \\
\hline $65-74$ & & 394/1317 (29.9) & $0.89(0.60,1.31)$ & $3.22(0.95,10.1)$ \\
\hline$\geq 75$ & & 498/1317 (37.8) & $0.85(0.58,1.24)$ & $14.6(4.56,46.6)$ \\
\hline Type of diabetes & 1317 & & & \\
\hline Type 2 & & $1166 / 1317(88.5)$ & 1 & 1 \\
\hline Type 1 & & $39 / 1317(3.0)$ & $0.73(0.35,1.56)$ & $0.44(0.11,1.86)$ \\
\hline Other & & $71 / 1317(5.4)$ & $1.33(0.80,2.20)$ & $1.50(0.77,2.93)$ \\
\hline Diagnosed on admission & & $41 / 1317(3.1)$ & $0.79(0.38,1.63)$ & - \\
\hline Ethnicity & 1035 & & & \\
\hline EU & & 641/1035 (61.9) & 1 & 1 \\
\hline MENA & & 196/1035 (18.9) & $0.98(0.69,1.40)$ & $0.87(0.52,1.47)$ \\
\hline $\mathrm{AC}$ & & $174 / 1035(16.8)$ & $0.96(0.66,1.40)$ & $0.78(0.44,1.37)$ \\
\hline AS & & $24 / 1035(2.3)$ & $1.51(0.65,3.52)$ & - \\
\hline BMI $\left(\mathrm{kg} / \mathrm{m}^{2}\right)^{\mathrm{a}}$ & 1117 & $28.4[25.0-32.7]$ & $1.25(1.09,1.42)$ & $0.95(0.78,1.16)$ \\
\hline BMI class & 1117 & & & \\
\hline$<25 \mathrm{~kg} / \mathrm{m}^{2}$ & & $279 / 1117(25)$ & 1 & 1 \\
\hline $25-29.9 \mathrm{~kg} / \mathrm{m}^{2}$ & & $410 / 1117(36.7)$ & $1.33(0.93,1.89)$ & $0.70(0.42,1.16)$ \\
\hline $30-39.9 \mathrm{~kg} / \mathrm{m}^{2}$ & & $359 / 1117(32.1)$ & $1.71(1.20,2.43)$ & $0.76(0.45,1.27)$ \\
\hline$\geq 40 \mathrm{~kg} / \mathrm{m}^{2}$ & & $69 / 1117(6.2)$ & $1.28(0.70,2.32)$ & $0.74(0.29,1.84)$ \\
\hline Diabetes duration (years) & 772 & $13.6 \pm 10.9$ & $1.00(0.98,1.01)$ & $1.01(0.99,1.04)$ \\
\hline $\mathrm{HbA}_{1 \mathrm{c}}(\mathrm{mmol} / \mathrm{mol})^{\mathrm{a}}$ & 846 & $65.4 \pm 21.2$ & $0.99(0.99,1.00)$ & $1.00(0.99,1.02)$ \\
\hline $\operatorname{HbA}_{1 \mathrm{c}}(\%)^{\mathrm{a}}$ & 846 & $8.1 \pm 1.9$ & $0.94(0.86,1.03)$ & $1.02(0.87,1.19)$ \\
\hline $\mathrm{HbA}_{1 \mathrm{c}}$ (categories) & 846 & & & \\
\hline$<53 \mathrm{mmol} / \mathrm{mol}(7 \%)$ & & $245 / 846(29.0)$ & 1 & 1 \\
\hline $53-63 \mathrm{mmol} / \mathrm{mol}(7-7.9 \%)$ & & $228 / 846(27.0)$ & $0.84(0.55,1.27)$ & $1.55(0.82,2.93)$ \\
\hline $64-74 \mathrm{mmol} / \mathrm{mol}(8-8.9 \%)$ & & $164 / 846(19.4)$ & $0.92(0.59,1.45)$ & $1.09(0.52,2.28)$ \\
\hline$\geq 75 \mathrm{mmol} / \mathrm{mol}(9 \%)$ & & 209/846 (24.7) & $0.78(0.51,1.21)$ & $0.84(0.40,1.75)$ \\
\hline Hypertension & 1299 & $1003 / 1299(77.2)$ & $1.23(0.92,1.65)$ & $1.82(1.11,2.98)$ \\
\hline Dyslipidaemia & 1255 & $640 / 1255(51.0)$ & $1.07(0.84,1.37)$ & $1.21(0.84,1.74)$ \\
\hline Tobacco use & 1029 & & & \\
\hline Never & & $582 / 1029(56.6)$ & 1 & 1 \\
\hline Former & & $390 / 1029(37.9)$ & $1.21(0.91,1.61)$ & $1.00(0.64,1.57)$ \\
\hline Current & & $57 / 1029(5.5)$ & $1.54(0.87,2.74)$ & $1.20(0.49,2.93)$ \\
\hline \multicolumn{5}{|l|}{ Long, term diabetes complications } \\
\hline Microvascular complications & 883 & $413 / 883(46.8)$ & $1.28(0.94,1.73)$ & $5.25(3.03,9.10)$ \\
\hline Severe diabetic retinopathy & 954 & $66 / 954(6.9)$ & $1.22(0.71,2.11)$ & $2.05(1.03,4.07)$ \\
\hline Diabetic kidney disease & 1066 & $355 / 1066(33.3)$ & $1.03(0.78,1.37)$ & $3.19(2.09,4.87)$ \\
\hline History of diabetic foot ulcer & 1232 & $76 / 1232(6.2)$ & $0.67(0.38,1.18)$ & $1.53(0.79,2.99)$ \\
\hline Macrovascular complications & 1189 & $485 / 1189(40.8)$ & $1.18(0.91,1.52)$ & $3.58(2.41,5.31)$ \\
\hline Ischaemic heart disease (ACS/CAR) & 1251 & $336 / 1251(26.9)$ & $1.04(0.79,1.37)$ & $2.65(1.84,3.82)$ \\
\hline Cerebrovascular disease (stroke or TIA) & 1267 & 163/1267 (12.9) & $1.02(0.71,1.47)$ & $2.19(1.4,3.42)$ \\
\hline Peripheral artery disease (major amputation/LLAR) & 1285 & 145/1285 (11.3) & $0.91(0.61,1.34)$ & $1.97(1.23,3.17)$ \\
\hline
\end{tabular}


Table 1 (continued)

\begin{tabular}{|c|c|c|c|c|}
\hline Clinical features & $\begin{array}{l}\text { Number of people } \\
\text { with available data }\end{array}$ & All & $\begin{array}{l}\text { Primary outcome }(n=382) \\
\text { OR }(95 \% \text { CI) }\end{array}$ & $\begin{array}{l}\text { Death }(n=140) \\
\text { OR }(95 \% \text { CI })\end{array}$ \\
\hline \multicolumn{5}{|l|}{ Comorbidities } \\
\hline Heart failure & 1206 & 140/1206 (11.6) & $0.78(0.52,1.17)$ & $2.28(1.42,3.66)$ \\
\hline NAFLD or liver cirrhosis & 1107 & 119/1107 (10.7) & $1.23(0.81,1.86)$ & $0.70(0.34,1.41)$ \\
\hline Active cancer & 1282 & $194 / 1282(15.1)$ & $1.08(0.77,1.50)$ & $1.55(0.99,2.42)$ \\
\hline COPD & 1278 & $133 / 1278(10.4)$ & $0.96(0.64,1.43)$ & $1.36(0.80,2.32)$ \\
\hline Treated OSA & 1189 & $144 / 1189(12.1)$ & $1.44(0.99,2.08)$ & $1.81(1.12,2.93)$ \\
\hline Organ graft & 1302 & $38 / 1302(2.9)$ & $1.14(0.57,2.28)$ & $0.46(0.11,1.93)$ \\
\hline End stage renal failure & 831 & $60 / 831(7.2)$ & $0.66(0.35,1.27)$ & $0.62(0.24,1.60)$ \\
\hline \multicolumn{5}{|l|}{ Routine treatment before admission } \\
\hline Metformin & 1317 & $746 / 1317(56.6)$ & $0.95(0.75,1.21)$ & $0.59(0.42,0.84)$ \\
\hline Sulfonylurea/glinides & 1317 & $367 / 1317(27.9)$ & $1.03(0.79,1.34)$ & $0.74(0.49,1.13)$ \\
\hline DPP-4 inhibitors & 1317 & 285/1317 (21.6) & $1.01(0.75,1.34)$ & $0.85(0.55,1.32)$ \\
\hline GLP1-RA & 1317 & $123 / 1317(9.3)$ & $1.36(0.92,2.01)$ & $0.64(0.32,1.29)$ \\
\hline Insulin & 1317 & $504 / 1317(38.3)$ & $1.01(0.79,1.29)$ & $1.71(1.20,2.43)$ \\
\hline Loop diuretics & 1317 & 252/1317 (19.1) & $1.10(0.81,1.48)$ & $2.49(1.70,3.64)$ \\
\hline Thiazide diuretics & 1317 & $267 / 1317(20.3)$ & $1.08(0.81,1.45)$ & $0.98(0.63,1.52)$ \\
\hline Potassium-sparing diuretics & 1317 & $59 / 1317(4.5)$ & $1.17(0.67,2.05)$ & $1.77(0.88,3.58)$ \\
\hline MRA & 1317 & $53 / 1317(4.0)$ & $0.96(0.52,1.78)$ & $2.03(1.00,4.13)$ \\
\hline$\beta$-blockers & 1317 & $442 / 1317(33.6)$ & $1.03(0.80,1.32)$ & $1.84(1.29,2.62)$ \\
\hline ACE inhibitors & 1317 & $354 / 1317(26.9)$ & $1.17(0.90,1.52)$ & $1.43(0.99,2.08)$ \\
\hline ARBs & 1317 & $389 / 1317(29.5)$ & $1.22(0.94,1.57)$ & $1.15(0.79,1.67)$ \\
\hline ARBs and/or ACE inhibitors & 1317 & $737 / 1317(56.0)$ & $1.32(1.03,1.68)$ & $1.58(1.09,2.28)$ \\
\hline ARBs and/or ACE inhibitors and/or MRA & 1317 & $752 / 1317(57.1)$ & $1.29(1.01,1.65)$ & $1.67(1.15,2.43)$ \\
\hline Statins & 1317 & $627 / 1317(47.6)$ & $1.03(0.81,1.31)$ & $1.19(0.84,1.68)$ \\
\hline
\end{tabular}

Data are presented as numbers $(\%)$ and mean $\pm \mathrm{SD}$, or median [25th-75th percentile] if not normally distributed

${ }^{a}$ For quantitative variables, OR corresponds to an increase of 1 SD. Only BMI was natural log transformed before OR calculation

Ethnicity: EU (Europid), MENA (Middle East North Africa); AC (African or Caribbean), AS (Asian)

$\mathrm{HBA}_{1 \mathrm{c}}$ corresponds to the $\mathrm{HBA}_{1 \mathrm{c}}$ value determined in the 6 months prior to or in the first 7 days following hospital admission

Diabetic kidney disease defined as eGFR $\leq 60 \mathrm{ml} \mathrm{min}^{-1}[1.73 \mathrm{~m}]^{-2}$ and/or proteinuria

MRAs include spironolactone and eplerenone

ACS, acute coronary syndrome; CAR, coronary artery revascularisation; COPD, chronic obstructive pulmonary disease; GLP1-RA, glucagon-like peptide 1-receptor agonist; LLAR, lower limb artery revascularisation; NAFLD, non-alcoholic fatty liver disease; TIA, transient ischaemic attack

were given as number (percentage) of participants. As prespecified in the protocol, the main objective of the study was descriptive. We calculated that a population size of 300 participants with an attrition of $20 \%$ for missing data, and a percentage of $16 \%$ of our main outcome, would give us a $95 \%$ CI equal to $11.7-21.1 \%$ using the Clopper-Pearson estimate.

Univariate logistic regression models were used to calculate OR associated with primary outcome or death on day 7 . Natural log transformation was consistently considered in cases of skewed distribution, which applied to BMI and biological features.

Age- and sex-adjusted ORs for the primary outcome were plotted for BMI, $\mathrm{HbA}_{1 \mathrm{c}}$ and admission plasma glucose using degree 2 fractional polynomial approaches [16].
Multivariable logistic regression models were used to separately assess the association of the primary outcome and death on day 7 with clinical and biological features. A standardisation process was also applied using $z$ scores for the purpose of direct comparison. In our initial statistical analysis plan, four covariates were systematically forced in the models: age, sex, $\mathrm{BMI}$ and $\mathrm{HbA}_{1 \mathrm{c}}$. However, since $\mathrm{HbA}_{1 \mathrm{c}}$ did not contribute to the risk of either the primary outcome or death on day 7, and owing to a significant number of missing data for $\mathrm{HbA}_{1 \mathrm{c}}$ and $\mathrm{BMI}$, our multivariable models ultimately took only age and sex into account. Other variables were considered only if associated with the main outcome in univariate analysis (threshold: two-sided $p$ value $\leq 0.10$ ) and selected in the final model after a stepwise backward/forward 
Table 2 COVID-19-related clinical, radiological and biological characteristics on admission in CORONADO participants, according to primary outcome (tracheal intubation and/or death within 7 days of admission), and death on day 7

\begin{tabular}{|c|c|c|c|c|}
\hline Characteristic & $\begin{array}{l}\text { Number of people } \\
\text { with available data }\end{array}$ & All & $\begin{array}{l}\text { Primary outcome } \\
(n=382) \\
\text { OR }(95 \% \mathrm{CI})\end{array}$ & $\begin{array}{l}\text { Death }(n=140) \\
\text { OR }(95 \% \text { CI })\end{array}$ \\
\hline COVID-19 symptoms & 1313 & $1237 / 1313(94.2)$ & $3.20(1.58,6.49)$ & $2.21(0.79,6.13)$ \\
\hline Time between symptom onset and hospital admission (days) & 1302 & $5[2-8]$ & $1.01(0.99,1.03)$ & $0.96(0.92,0.99)$ \\
\hline \multicolumn{5}{|l|}{ Clinical presentation } \\
\hline Fever & 1288 & 1003/1288 (77.9) & $1.07(0.80,1.44)$ & $0.73(0.49,1.10)$ \\
\hline Fatigue & 1239 & $773 / 1239(62.4)$ & $1.15(0.89,1.49)$ & $1.13(0.77,1.65)$ \\
\hline Cough & 1270 & $872 / 1270(68.7)$ & $0.99(0.76,1.29)$ & $0.87(0.59,1.28)$ \\
\hline Cephalalgia & 1193 & $157 / 1193(13.2)$ & $0.85(0.58,1.25)$ & $0.44(0.21,0.92)$ \\
\hline Dyspnoea & 1292 & $798 / 1292(61.8)$ & $2.56(1.95,3.36)$ & $2.29(1.51,3.47)$ \\
\hline Rhinitis and/or pharyngeal symptoms & 1178 & $111 / 1178(9.4)$ & $0.78(0.49,1.23)$ & $0.39(0.16,0.99)$ \\
\hline Ageusia and/or anosmia & 1073 & 136/1073 (12.7) & $0.73(0.47,1.12)$ & $0.34(0.14,0.85)$ \\
\hline Digestive disorders & 1236 & $427 / 1236(34.5)$ & $0.83(0.64,1.08)$ & $0.88(0.60,1.30)$ \\
\hline \multicolumn{5}{|l|}{ Chest CT imaging } \\
\hline Abnormal chest $\mathrm{CT}$ & 896 & $844 / 896(94.2)$ & $1.16(0.61,2.21)$ & - \\
\hline Ground-glass opacity/crazy paving & 818 & $736 / 818(90.0)$ & $1.83(1.02,3.28)$ & $1.70(0.66,4.32)$ \\
\hline \multicolumn{5}{|l|}{ Biological findings } \\
\hline Positive SARS-CoV-2 PCR & 1268 & $1227 / 1268(96.8)$ & $2.44(1.02,5.85)$ & $1.54(0.47,5.06)$ \\
\hline Admission plasma glucose $(\mathrm{mmol} / \mathrm{l})^{\mathrm{a}}$ & 940 & $9.20[6.80-12.62]$ & $1.28(1.12,1.48)$ & $1.20(0.98,1.46)$ \\
\hline Plasma creatinine $(\mu \mathrm{mol} / \mathrm{l})^{\mathrm{a}}$ & 1196 & $91[69-133]$ & $1.24(1.10,1.40)$ & $1.56(1.33,1.82)$ \\
\hline eGFR $\left(\mathrm{ml} \mathrm{min} \min ^{-1}[1.73 \mathrm{~m}]^{-2}\right)^{\mathrm{a}}$ & 1196 & 69 [41.7-89.5] & $0.82(0.73,0.93)$ & $0.61(0.52,0.71)$ \\
\hline $\operatorname{ALT}(\% \mathrm{ULN})^{\mathrm{a}}$ & 1068 & $0.62[0.41-0.99]$ & $1.25(1.10,1.42)$ & $0.84(0.67,1.06)$ \\
\hline $\operatorname{AST}(\% \mathrm{ULN})^{\mathrm{a}}$ & 1053 & $1.05[0.75-1.51]$ & $1.78(1.54,2.06)$ & $1.34(1.14,1.59)$ \\
\hline GGT $(\% \text { ULN })^{\mathrm{a}}$ & 983 & $0.94[0.56-1.73]$ & $1.25(1.10,1.43)$ & $0.97(0.78,1.20)$ \\
\hline Haemoglobin $(\mathrm{g} / \mathrm{l})^{\mathrm{a}}$ & 1276 & 129 [114-143] & $0.95(0.84,1.07)$ & $0.96(0.81,1.14)$ \\
\hline White cell count $\left(10^{3} / \mathrm{mm}^{3}\right)^{\mathrm{a}}$ & 1269 & $6440[4930-8610]$ & $1.27(1.12,1.44)$ & $1.43(1.19,1.70)$ \\
\hline Lymphocyte count $\left(10^{3} / \mathrm{mm}^{3}\right)^{\mathrm{a}}$ & 1211 & $990[685-1400]$ & $0.69(0.60,0.80)$ & $0.75(0.60,0.92)$ \\
\hline Platelet count $\left(10^{3} / \mathrm{mm}^{3}\right)^{\mathrm{a}}$ & 1273 & $193[151-246]$ & $0.86(0.76,0.97)$ & $0.86(0.73,1.02)$ \\
\hline D-dimers $(\mu \mathrm{g} / \mathrm{l})^{\mathrm{a}}$ & 397 & $830[350-1571]$ & $0.93(0.76,1.15)$ & $1.25(0.84,1.86)$ \\
\hline $\mathrm{CRP}(\mathrm{mg} / \mathrm{l})^{\mathrm{a}}$ & 1208 & $77.8[38.4-132.7]$ & $1.99(1.69,2.34)$ & $1.49(1.20,1.84)$ \\
\hline $\mathrm{LDH}(\mathrm{UI} / \mathrm{l})^{\mathrm{a}}$ & 566 & $351[268-496]$ & $2.43(1.85,3.18)$ & $1.62(1.10,2.39)$ \\
\hline $\mathrm{CPK}(\mathrm{UI} / \mathrm{l})^{\mathrm{a}}$ & 549 & $145[72-319]$ & $1.56(1.30,1.88)$ & $1.68(1.31,2.17)$ \\
\hline Fibrinogen $(\mathrm{g} / \mathrm{l})^{\mathrm{a}}$ & 658 & $6.0[4.8-7.2]$ & $1.32(1.09,1.58)$ & $1.05(0.84,1.31)$ \\
\hline
\end{tabular}

Data are presented as numbers (\%) or median [25th-75th percentile] if not normally distributed

${ }^{a}$ All biological quantitative variables were natural log transformed. OR corresponds to an increase of $1 \mathrm{SD}$

eGFR was calculated according to the CKD-EPI formula

GGT, $\gamma$-glutamyl transferase; LDH, lactate dehydrogenase; ULN, upper limit of normal

selection process. In the event of obvious collinearity (such as alanine aminotransferase [ALT] with aspartate aminotransferase [AST], or white cell count with lymphocyte count), only the variable associated with the smaller $p$ value was considered for multivariable analysis. In the final model, interactions were checked between all pairs of covariates.

We built two distinct multivariable models both separately for the main outcome and for the risk of death: (1) the first included covariates related to patient history prior to admission (chronic diabetes complications and other comorbidities) and routine medications; (2) the second included covariates related to medical presentation on admission, such as COVID-19 symptoms and biological determinations. This corresponds to the situation of a physician in an emergency room or department, assessing the prognosis of his/her patient.

All statistical tests were two-sided with a type 1 error set at $5 \%$. All analyses were performed on available data, without imputation, and using statistical software $\mathrm{R}$ version 3.6.2 (https://cran.r-project.org/bin/windows/base/old/3.6.2/). 


\section{Results}

Population and clinical outcomes The present analysis focused on 1317 participants with diabetes and confirmed COVID-19 admitted to 53 French hospitals during the period 10-31 March 2020.

A total of 382 patients $(29.0 \%$; 95\% CI $26.6,31.5)$ met the primary outcome. Overall, 410 patients $(31.1 \%$; $95 \%$ CI 28.6, 33.7) were admitted to ICUs within 7 days of hospital admission, including 267 individuals who required tracheal intubation for mechanical ventilation $(20.3 \%$; $95 \%$ CI 18.1, 22.5). One hundred and forty deaths $(10.6 \%$; $95 \%$ CI 9.0, 12.4) were recorded on day 7. In contrast, 237 participants $(18.0 \%$; 95\% CI 16.0 , 20.2) were discharged on day 7 (see flowchart in Fig. 1).

Demographic and diabetes-related characteristics The clinical characteristics of the whole population are shown in Table 1. Mean $( \pm \mathrm{SD})$ age was $69.8 \pm 13.0$ years and $64.9 \%$ were men. The classification of diabetes cases mainly included type 2 diabetes $(88.5 \%)$, and less frequently type 1 diabetes $(3.0 \%)$ or other aetiologies $(5.4 \%)$. In addition, $3.1 \%$ of the participants were newly diagnosed with diabetes on admission $\left(\mathrm{HbA}_{1 \mathrm{c}} \geq 48 \mathrm{mmol} / \mathrm{mol}[6.5 \%]\right)$. The median BMI was 28.4 (25th-75th percentile $25.0-32.7) \mathrm{kg} / \mathrm{m}^{2}$. The mean $\mathrm{HbA}_{1 \mathrm{c}}$ value was $65 \pm 21 \mathrm{mmol} / \mathrm{mol}(8.1 \pm 1.9 \%)$. A medical history of hypertension and dyslipidaemia were found in $77.2 \%$ and $51.0 \%$ of the participants, respectively. Microvascular and macrovascular complications were reported in $46.8 \%$ and $40.8 \%$ of individuals, respectively. Regarding routine glucose-lowering medications, $38.3 \%$ of the participants were on insulin therapy while $56.6 \%$ received metformin and $21.6 \%$ dipeptidyl peptidase 4 (DPP-4) inhibitors. Moreover, treatment with renin-angiotensin-aldosterone system (RAAS) blockers (ACE inhibitors and/or angiotensin II receptor blockers [ARBs] and/or mineralocorticoid-receptor antagonists [MRAs]) and statins was used by $57.1 \%$ and $47.6 \%$ of the participants, respectively.

Characteristics of COVID-19 on admission Characteristics of COVID-19 on admission are provided in Table 2. The median duration of symptoms before admission was 5 days (25th-75th percentile, 2-8 days). As expected, the most common signs were fever (77.9\%), cough $(68.7 \%)$, fatigue $(62.4 \%)$, dyspnoea $(61.8 \%)$ and digestive disorders (34.5\%). SARS-CoV-2 PCR testing was performed in 1268 participants, with a positive result in $96.8 \%$. Thoracic CT imaging demonstrated typical ground-glass opacity and/or crazy paving in 818 individuals $(90.0 \%)$. Biological findings were consistent with obvious infection as illustrated by a median C-reactive protein (CRP) at 77.8 (38.4-132.7) $\mathrm{mg} / \mathrm{l}$. Median plasma glucose at admission was $9.20(6.80-12.62) \mathrm{mmol} / \mathrm{l}$.
Of interest, diabetes-related disorders were reported in $11.1 \%$ of the participants on admission with 132 episodes of severe hyperglycaemia, including 40 of ketosis, of which 19 were ketoacidosis, as well as 14 hypoglycaemic events, while severe anorexia was reported in 83 participants (6.3\%).

Factors prior to admission associated with study outcomes In univariate analysis considering the primary outcome, male sex was more frequent $(69.1 \%$ vs $63.2 \%, p=0.0420)$ and BMI was significantly higher (median 29.1 [25.9-33.6] vs 28.1 $\left.[24.8-32.0] \mathrm{kg} / \mathrm{m}^{2}, p=0.0009\right)$ in patients who met the primary outcome compared with the others, as was the use of RAAS blockers $(61.5 \%$ vs $55.3 \%, p=0.0386)$ (Table 1 and electronic supplementary material [ESM] Table 1).

Furthermore, several characteristics prior to admission were associated with the risk of death on day 7 including age, hypertension, micro- and macrovascular diabetic complications and comorbidities such as heart failure or treated obstructive sleep apnoea (OSA). Among prior medications, metformin use was lower in people who died. In contrast, insulin therapy, RAAS blockers, $\beta$-blockers, loop diuretics and MRAs were found to be associated with death on day 7 (Table 1 and ESM Table 1).

When using age- and sex-adjusted nonlinear models, BMI was significantly and positively associated with the primary outcome ( $p=0.0001)$ but not with death on day $7(p=0.1488)$ (Fig. 2). In contrast, $\mathrm{HbA}_{1 \mathrm{c}}$ level was neither associated with the primary outcome nor with death on day 7 .

Multivariable analyses were then conducted with characteristics prior to admission. BMI remained associated with the primary outcome in a model where sex and age were forced into models. When comorbidities and routine treatment were entered in an adjusted model with stepwise selection, BMI was the only independent factor associated with the primary outcome, with an adjusted OR of 1.28 (95\% CI 1.10, 1.47) (Table 3). Finally, age, history of microvascular or macrovascular complications, and treated OSA were found to be independently associated with the risk of death on day 7 (Table 4). A sensitivity analysis conducted only in patients with a positive SARS-CoV-2 PCR test found similar results for both the primary outcome and death (data not shown).

Factors on admission associated with study outcomes Regarding COVID-19 symptoms on admission, dyspnoea was positively associated with the primary outcome and with death on day 7 , whereas cephalalgia, upper respiratory tract symptoms (rhinitis and/or pharyngeal symptoms), and ageusia/anosmia, as well as time between symptom onset and admission, were negatively associated with death on day 7 (Table 2 and ESM Table 2). Several biological parameters reflecting the severity of the infection were also associated with both primary outcome and death on day 7 , such as CRP, 

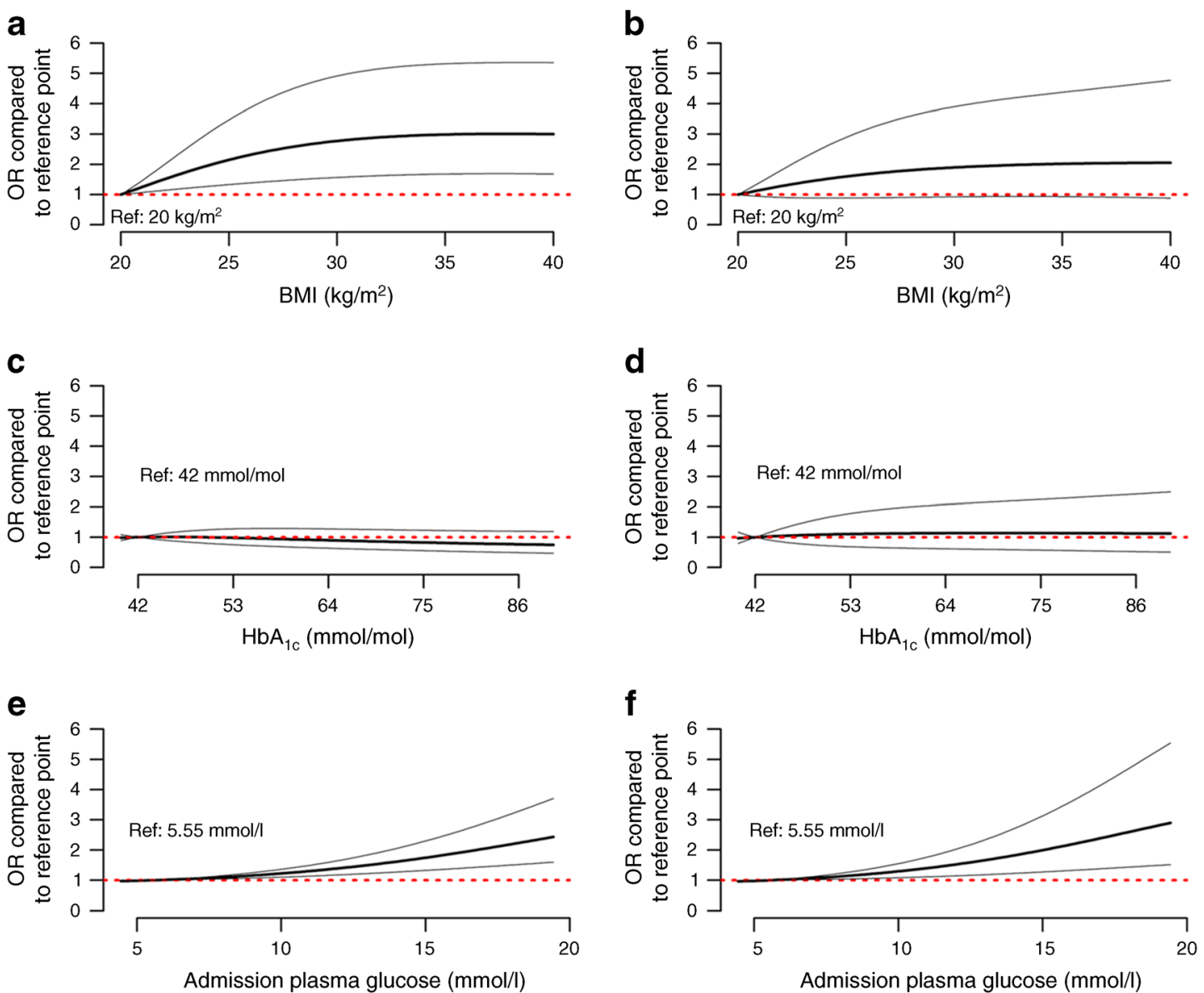

Fig. 2 Sex- and age-adjusted ORs for the main outcome and for death, using logistic regression models with degree 2 multiple fractional polynomials. (a, b) OR for BMI for the primary outcome $(\mathbf{a} ; p=0.0001)$ and for death $(\mathbf{b} ; p=0.1488)$ on day 7 (reference value $\left.20 \mathrm{~kg} / \mathrm{m}^{2} ; n=1117\right)$. (c, d) OR for $\mathrm{HbA}_{1 \mathrm{c}}$ for the primary outcome $(\mathbf{c} ; p=0.2897)$ and for death (d; $p=0.9129$ ) on day 7 (reference value $42 \mathrm{mmol} / \mathrm{mol} ; n=846)$. (e, f)

OR for admission plasma glucose for the primary outcome (e; $p=0.0001)$ and for death $(\mathbf{f} ; p=0.0059)$ on day 7 (reference value $5.55 \mathrm{mmol} / \mathrm{l} ; n=$ 940). The thick black line gives the OR compared with the reference point, the thin grey lines are the $95 \% \mathrm{CI}$, and the red dotted red line $(\mathrm{OR}=1)$ corresponds to a similar risk-level as the reference point

and sex-adjusted nonlinear models, admission plasma glucose was significantly and positively associated with the primary outcome $(p=0.0001)$ and with death on day $7(p=0.0059)$ (Fig. 2).

Table 3 Multivariable analysis of the primary outcome in CORONADO participants: covariables prior to admission

\begin{tabular}{|c|c|c|c|c|}
\hline \multirow[b]{2}{*}{ Patient characteristics } & \multicolumn{2}{|c|}{$\begin{array}{l}\text { Model 'prior to admission': } \\
\text { fully adjusted }\end{array}$} & \multicolumn{2}{|c|}{$\begin{array}{l}\text { Model 'prior to admission': } \\
\text { stepwise selection with age and sex forced }\end{array}$} \\
\hline & OR $(95 \% \mathrm{CI})$ & $p$ value & OR $(95 \% \mathrm{CI})$ & $p$ value \\
\hline Age (+1 SD) & $1.05(0.90,1.21)$ & 0.5495 & $1.06(0.92,1.22)$ & 0.4448 \\
\hline Sex (female/male) & $0.76(0.57,1.03)$ & 0.0777 & $0.75(0.56,1.01)$ & 0.0559 \\
\hline BMI (+1 SD) & $1.24(1.06,1.44)$ & 0.0064 & $1.28(1.10,1.47)$ & 0.0010 \\
\hline Treated OSA & $1.15(0.76,1.73)$ & 0.5036 & - & - \\
\hline ARBs and/or ACE inhibitors and/or MRAs & $1.15(0.86,1.54)$ & 0.3493 & - & - \\
\hline
\end{tabular}

Models were applied in 1020 participants yielding 281 primary outcomes $(27.5 \%)$

BMI was natural log transformed. For quantitative variables, OR corresponds to an increase of $1 \mathrm{SD}$ after standardisation

MRAs include spironolactone and eplerenone 
Table 4 Multivariable analysis of the risk of death on day 7 in CORONADO participants: covariables prior to admission

\begin{tabular}{llllll}
\hline & $\begin{array}{l}\text { Model 'prior to admission': } \\
\text { fully adjusted }\end{array}$ & $\begin{array}{l}\text { Model 'prior to admission': } \\
\text { stepwise selection with age and } \\
\text { sex forced }\end{array}$ \\
\cline { 2 - 3 } Patient characteristics & OR $(95 \% \mathrm{CI})$ & $p$ value & OR $(95 \% \mathrm{CI})$ & $p$ value \\
\hline Age (+1 SD) & $2.39(1.67,3.42)$ & $<0.0001$ & $2.48(1.74,3.53)$ & $<0.0001$ \\
Sex (female/male) & $0.78(0.43,1.40)$ & 0.4023 & $0.78(0.44,1.38)$ & 0.4007 \\
Hypertension & $0.76(0.34,1.70)$ & 0.5087 & - & - \\
Microvascular complications & $1.78(0.92,3.44)$ & 0.0846 & $2.14(1.16,3.94)$ & 0.0153 \\
Macrovascular complications & $2.26(1.25,4.08)$ & 0.0069 & $2.54(1.44,4.50)$ & 0.0013 \\
Heart failure & $1.08(0.54,2.15)$ & 0.8249 & - & - \\
Active cancer & $1.45(0.77,2.73)$ & 0.2458 & - & - \\
Treated OSA & $2.65(1.36,5.19)$ & 0.0044 & $2.80(1.46,5.38)$ & 0.0020 \\
$\beta$-Blockers & $1.19(0.69,2.06)$ & 0.5321 & - & - \\
Metformin & $0.80(0.45,1.43)$ & 0.4532 & - & - \\
Insulin & $1.26(0.72,2.22)$ & 0.4130 & - & - \\
Loop diuretics & $1.39(0.76,2.55)$ & 0.2806 & - & - \\
ARBs and/or ACE inhibitors and/or MRAs & $1.22(0.68,2.20)$ & 0.5069 & - & - \\
\hline
\end{tabular}

Models were applied to 758 participants yielding 74 deaths (9.8\%)

The OR for age corresponds to an increase of $1 \mathrm{SD}$ after standardisation

MRAs include spironolactone and eplerenone
The prognostic value of characteristics on admission was finally investigated in multivariable models (Table 5). Among clinical symptoms, dyspnoea was the only predictor of the primary outcome. Regarding biological parameters, lymphopaenia on admission was independently associated with the primary outcome, as were increased AST and CRP concentrations. Dyspnoea and plasma levels of both AST and CRP were also independently associated with the risk of death on day 7, as well as decrease in platelet count and eGFR (Table 6). Once again, similar results were obtained for both the primary outcome and death on day 7 when considering only the patients with a positive PCR test (data not shown).
Table 5 Multivariable analysis of the primary outcome in CORONADO participants: covariables on admission

\begin{tabular}{|c|c|c|c|c|}
\hline \multirow[b]{2}{*}{ Patient characteristics } & \multicolumn{2}{|c|}{$\begin{array}{l}\text { Model 'on admission': } \\
\text { fully adjusted }\end{array}$} & \multicolumn{2}{|c|}{$\begin{array}{l}\text { Model 'on admission': } \\
\text { stepwise selection with age and sex } \\
\text { forced }\end{array}$} \\
\hline & OR $(95 \% \mathrm{CI})$ & $p$ value & OR $(95 \% \mathrm{CI})$ & $p$ value \\
\hline Age (+1 SD) & $0.98(0.77,1.25)$ & 0.8569 & $1.02(0.81,1.28)$ & 0.8981 \\
\hline Sex (female/male) & $1.46(0.88,2.41)$ & 0.1410 & $1.44(0.89,2.32)$ & 0.1417 \\
\hline BMI (+1 SD) & $1.13(0.89,1.43)$ & 0.3297 & - & - \\
\hline Dyspnoea & $2.17(1.34,3.50)$ & 0.0015 & $2.10(1.31,3.35)$ & 0.0020 \\
\hline Admission plasma glucose (+1 SD) & $1.14(0.92,1.42)$ & 0.2391 & - & - \\
\hline eGFR (+1 SD) & $0.81(0.64,1.01)$ & 0.0643 & - & - \\
\hline AST (+1 SD) & $2.19(1.65,2.90)$ & $<0.0001$ & $2.23(1.70,2.93)$ & $<0.0001$ \\
\hline Lymphocyte count (+1 SD) & $0.70(0.53,0.94)$ & 0.0161 & $0.67(0.50,0.88)$ & 0.0050 \\
\hline Platelet count (+1 SD) & $0.80(0.63,1.01)$ & 0.0623 & - & - \\
\hline $\mathrm{CRP}(+1 \mathrm{SD})$ & $2.00(1.47,2.73)$ & $<0.0001$ & $1.93(1.43,2.59)$ & $<0.0001$ \\
\hline
\end{tabular}

Models were applied to 619 participants yielding 177 primary outcomes $(28.6 \%)$

For quantitative variables, OR corresponds to an increase of $1 \mathrm{SD}$ after natural log transformation and standardisation, except for age, which was not natural log transformed

eGFR was calculated according to the CKD-EPI formula 
Table 6 Multivariable analysis of the risk of death on day 7 in CORONADO participants: covariables on admission

\begin{tabular}{|c|c|c|c|c|}
\hline \multirow[b]{2}{*}{ Patient characteristics } & \multicolumn{2}{|c|}{$\begin{array}{l}\text { Model 'clinical and } \\
\text { biological': } \\
\text { fully adjusted }\end{array}$} & \multicolumn{2}{|c|}{$\begin{array}{l}\text { Model 'clinical and biological': } \\
\text { stepwise selection with age and } \\
\text { sex forced }\end{array}$} \\
\hline & OR $(95 \% \mathrm{CI})$ & $p$ value & OR $(95 \% \mathrm{CI})$ & $p$ value \\
\hline Age (+1 SD) & $4.28(2.64,6.94)$ & $<0.0001$ & $4.12(2.59,6.55)$ & $<0.0001$ \\
\hline Sex (female/male) & $0.92(0.44,1.92)$ & 0.8237 & $1.02(0.50,2.09)$ & 0.9523 \\
\hline Cephalalgia & $1.55(0.43,5.58)$ & 0.5029 & - & - \\
\hline Dyspnoea & $2.73(1.30,5.73)$ & 0.0079 & $2.80(1.37,5.72)$ & 0.0049 \\
\hline Rhinitis and/or pharyngeal signs & $0.46(0.11,1.96)$ & 0.2957 & - & - \\
\hline Ageusia and/or anosmia & $1.31(0.43,4.01)$ & 0.6403 & - & - \\
\hline Admission plasma glucose (log, $+1 \mathrm{SD})$ & $1.30(0.94,1.82)$ & 0.1148 & - & - \\
\hline eGFR (log, +1 SD) & $0.51(0.37,0.69)$ & $<0.0001$ & $0.51(0.38,0.69)$ & $<0.0001$ \\
\hline $\operatorname{AST}(\log ,+1 \mathrm{SD})$ & $1.93(1.38,2.71)$ & 0.0001 & $1.85(1.33,2.56)$ & 0.0003 \\
\hline White cell count $(\log ,+1 \mathrm{SD})$ & $1.29(0.86,1.92)$ & 0.2126 & - & - \\
\hline Platelet count $(\log ,+1 \mathrm{SD})$ & $0.66(0.47,0.92)$ & 0.0144 & $0.71(0.53,0.97)$ & 0.0292 \\
\hline CRP (log, +1 SD) & $1.70(1.09,2.66)$ & 0.0202 & $1.87(1.20,2.89)$ & 0.0052 \\
\hline
\end{tabular}

Models were applied to 612 participants yielding 59 primary outcomes $(9.6 \%)$

For quantitative variables, OR corresponds to an increase of $1 \mathrm{SD}$ after natural log transformation and standardisation, except for age, which was also standardised but not natural log transformed

eGFR was calculated according to the CKD-EPI formula

\section{Discussion}

CORONADO is the first study specifically dedicated to people with diabetes infected with SARS-CoV-2 and admitted to hospital. CORONADO was designed to address three main goals: (1) assess the phenotypic characteristics of patients with diabetes hospitalised for COVID-19; (2) estimate the prevalence of the primary outcome, which combines death and tracheal intubation for mechanical ventilation within the first 7 days following admission; (3) identify in this specific population certain prognostic factors associated with early severity of COVID-19. When considering variables prior to admission, our results support no independent association between a severe course of COVID-19 and age, sex, long-term glucose control, chronic complications, hypertension or usual medications, including RAAS blockers and DPP-4 inhibitors. Only BMI turned out to be independently associated with the primary outcome. When considering variables on admission, dyspnoea, lymphopaenia, and increased AST and CRP levels were independent prognostic factors for severe course of COVID-19.

To our knowledge, CORONADO is the first study that provides precise information regarding the characteristics of diabetes in the severe forms of COVID-19. The study population roughly resembles the French population of people living with diabetes, except for $\mathrm{HbA}_{1 \mathrm{c}}$, which was clearly higher in our study $(65 \mathrm{mmol} / \mathrm{mol}[8.1 \%])$ compared with the nationwide ENTRED-2 survey participants older than
65 years $(54 \mathrm{mmol} / \mathrm{mol}[7.1 \%])$ [17]. Of note, there was no overrepresentation of declared type 1 diabetes (only $3.0 \%$ of participants) in people with diabetes hospitalised for COVID19.

The primary outcome occurred in $29.0 \%$ of CORONADO participants. While the design of the present study did not enable comparison of the severity of COVID-19 in people with or without diabetes, $20.3 \%$ of the study population required tracheal intubation for mechanical ventilation with a mortality rate of $10.6 \%$ as early as 7 days after admission. The severity of the prognosis of COVID-19 observed in people with diabetes in the present study is in accordance with previous epidemiological studies [10-13, 18, 19], and metaanalyses $[14,20]$. An important issue is the choice of our primary endpoint, which combines death (an unequivocal outcome) with tracheal intubation for mechanical ventilation. It should be emphasised that the latter outcome can result from different factors, which were impossible to standardise in all centres, such as (1) clinical deterioration, (2) refusal to be intubated, or (3) futility (i.e. a medical decision not to intubate), leading to potentially fewer patients actually intubated compared with those meeting intubation criteria.

Regarding the clinical characteristics of COVID-19 in CORONADO participants, there was a high prevalence of fever and respiratory symptoms (cough, dyspnoea) and, to a lesser extent, digestive disorders. In addition to symptoms directly related to COVID-19, people with diabetes can also require management of acute metabolic disorders. In 
particular, physicians should be warned not only of the risk of ketoacidosis but also of hypoglycaemia, probably favoured by COVID-19-induced anorexia without concomitant adaptation of glucose-lowering drugs.

With the aim of providing clinicians with criteria to evaluate the risk of severe COVID-19 on an individual level in people with diabetes, we performed multivariable analyses to identify pre-admission and on-admission prognostic factors. Since some preclinical studies previously highlighted potential mechanistic links between glucose control, immune response and MERS-CoV infection [21], we were particularly interested in studying the relationship between long-term glucose control and COVID-19 prognosis. In fact, we failed to find any association between $\mathrm{HbA}_{1 \mathrm{c}}$ (even with the highest values, $>75 \mathrm{mmol} / \mathrm{mol}[9.0 \%]$ ) and either the primary outcome or death on day 7. On the basis of this result and in order to increase the sample size for our analyses, we decided not to force $\mathrm{HbA}_{1 \mathrm{c}}$ in the multivariate models.

An interesting finding is the association of BMI with study outcomes. Indeed, in our study, BMI was positively and independently associated with the primary outcome, which is largely driven by tracheal intubation. Interestingly, a recent report on COVID-19 patients in ICU showed an association between $\mathrm{BMI}$ and the requirement for mechanical ventilation, irrespective of diabetic status [22]. However, such an association with BMI was no longer statistically significant when considering death on day 7 . It should also be noted that the increased risk for the primary outcome appears to be less pronounced in patients with morbid obesity (grade 3, BMI $\geq 40 \mathrm{~kg} / \mathrm{m}^{2}$ ) compared with those who were overweight or with grade 1-2 obesity, a situation previously described as the 'obesity paradox' in ICUs [23]. Additional studies are clearly warranted to decipher the link between obesity, metabolic complications and COVID-19 severity with specific attention to fat mass distribution, insulin resistance and inflammatory/immune profiles.

While hypertension was previously reported as the most prevalent comorbidity in the general population with severe COVID-19 [2, 9, 12], it was not independently associated with the severity of the disease in the study. In addition, RAAS blockers (ACE inhibitors, ARBs and MRAs) were not independently associated with the main outcome, supporting the recent recommendation not to discontinue RAAS blockade [24]. Moreover, we found no association between glucose-lowering drugs, including DPP-4 inhibitors, that have been suggested to potentially interfere with coronavirus infection and COVID-19 prognosis [21, 25].

Our complementary multivariable approach was suitable for the identification of characteristics on admission associated with COVID-19 prognosis, of particular relevance for the management of people with diabetes in the setting of an emergency room. Notably, we found an age- and sex-independent association between increased admission plasma glucose levels and the severity of COVID-19, as previously reported in critically ill patients [26]. However, we speculate that this observation is rather the consequence of the severity of the infection than a causal primary factor.

Another important result concerns the identification of the prognostic factors of early death in people with diabetes and COVID-19. Compared with the primary outcome, which reflects aggressive management in ICUs with tracheal intubation, death on day 7 was more prevalent in elderly participants with an OR $>14$ for people older than 75 years, compared with younger individuals. In addition, these individuals also very frequently exhibited complications of diabetes (microvascular and macrovascular complications, mainly coronary heart disease) as well as pulmonary diseases (such as OSA). As expected, they were also more frequently on insulin therapy and taking multiple drugs (such as diuretics). Conversely, metformin use was associated with a reduced risk of early death, probably reflecting a less advanced stage of diabetes with fewer comorbidities (such as severe chronic kidney disease) that contraindicate its use. In multivariable analyses, age, diabetic complications and treated OSA remained significantly and independently associated with death on day 7 . In addition, dyspnoea, reduced eGFR and platelet count, and increased AST and CRP on admission were independent markers of early death.

The discrepancy between the primary combined outcome (mainly driven by tracheal intubation) and death on day 7 could be explained by the fact that there were medical decisions not to pursue aggressive therapy in this frail population. In contrast, our data can be considered reassuring for the majority of people living with type 1 diabetes. Indeed, there was no death in participants with type 1 diabetes younger than 65 years. Additional data collection is currently ongoing to provide a precise picture of the rare individuals with type 1 diabetes hospitalised for COVID-19.

Some limitations must be acknowledged in the current analysis. We focused on hospitalised COVID-19 cases and our results cannot be generalised to all people with COVID19 and diabetes, especially those with a less severe form of the disease. A secondary limitation is the size of our study population and the large proportion (i.e. 35.7\%) of patients without available $\mathrm{HbA}_{1 \mathrm{c}}$. This is in accordance with the observation that only $55 \%$ of the people with diabetes had had three or more $\mathrm{HbA}_{1 \mathrm{c}}$ determinations in the previous year according to French national registry data [27]. Finally, the present report focuses only on short-term prognosis (i.e. 7 days after admission) and one cannot exclude the possibility that diabetes characteristics prior to admission could be associated with severe COVID-19 outcomes in the longer term. However, strengths must be acknowledged such as the originality of the medical question leading to the CORONADO initiative and the inclusion of participants on a national basis. In addition, a large majority (>93\%) of COVID-19 cases were confirmed with a 
positive PCR test, with few cases diagnosed from medical and/or radiological observations only. We also structured data collection in order to obtain a precise and standardised recording of phenotypic characteristics of the diabetic study population.

In conclusion, the CORONADO study refined the phenotypes of COVID-19 individuals with diabetes admitted to hospital and showed that chronic glycaemic control did not impact the immediate severity of COVID-19. Elderly populations with long-term diabetes with advanced diabetic complications and/or treated OSA were particularly at risk of early death, and might require specific management to avoid contamination with SARS-CoV-2. BMI also appears as an independent prognostic factor for COVID-19 severity in the population living with diabetes, requiring hospital admission.

Acknowledgements We thank the sponsor (DRCI [délégation à la recherche clinique et à l'innovation] CHU Nantes), the Clinical Project Manager (M. Saignes, CHU Nantes, Nantes, France) and assistant (J. Saunier, CHU Nantes, Nantes, France), Clinical Research Associates (S. El Andaloussi [CHU Nantes, Nantes, France], J. Martin-Gauthier [CHU Nantes, Nantes, France], E. Rebouilleau, [CHU Nantes, Nantes, France]) and data managers (B. Guyomarch [CHU Nantes, Nantes, France], T. Roman [CHU Nantes, Nantes, France]). We are grateful to P. Tucker (Trets, France) for editing the manuscript. We acknowledge all medical staff involved in the diagnosis and treatment of patients with COVID-19 in participating centres. We thank all general practitioners, specialists, pharmacists and biological laboratories responsible for hospitalised patients for providing additional medical information to investigators. We thank the Société Francophone du Diabète (SFD) and Société Française d'Endocrinologie (SFE) for disseminating the study design and organisation, and the Fédération Française des Diabétiques (FFD) for participating in the study organisation.

Data availability A data-sharing statement is available in the ESM.

Funding This study received the following funding: the Fondation Francophone de Recherche sur le Diabète (FFRD), supported by Novo Nordisk, MSD, Abbott, AstraZeneca, Lilly and FFD (Fédération Française des Diabétiques) - CORONADO initiative emergency grant; Société Francophone du Diabète (SFD) - CORONADO initiative emergency grant; Air Liquide Health Care international. All research facilities are acknowledged for providing research associates and research technicians for clinical investigations pro bono. The funders of the study had no role in study design, data collection, data analysis, data interpretation or writing of the report. The corresponding authors (BC and $\mathrm{SH}$ ) had full access to all the data in the study and had final responsibility for the decision to submit for publication.

Authors' relationships and activities $\mathrm{BC}$ reports grants and personal fees from Amgen, personal fees from AstraZeneca, personal fees from Akcea, personal fees from Genfit, personal fees from Gilead, personal fees from Eli Lilly, personal fees from Novo Nordisk, personal fees from MSD, grants and personal fees from Sanofi, and grants and personal fees from Regeneron. SH reports personal fees and non-financial support from AstraZeneca, grants and personal fees from Bayer, personal fees from Boehringer Ingelheim, grants from Dinno Santé, personal fees from Eli Lilly, non-financial support from LVL, personal fees and non-financial support from MSD, personal fees from Novartis, grants from Pierre Fabre Santé, personal fees and non-financial support from Sanofi, personal fees and non-financial support from Servier, and personal fees from Valbiotis. MP reports personal fees and non-financial support from Novo Nordisk, non-financial support from Sanofi, and non-financial support from Amgen. SB reports personal fees from Novo Nordisk, personal fees from Sanofi, personal fees from Eli Lilly, personal fees from Medtronic, and personal fees from Abbott. PD reports personal fees from Novo Nordisk, personal fees from Sanofi, personal fees from Eli Lilly, personal fees from MSD, personal fees from Novartis, personal fees from Abbott, personal fees from AstraZeneca, personal fees from Boehringer Ingelheim, and personal fees from Mundipharma. BG reports personal fees from Eli Lilly, personal fees from Novo Nordisk, personal fees from Mellitus Care, personal fees from Isis Diabetes, and grants from Boehringer Ingelheim. MJ reports personal fees and non-financial support from Sanofi, personal fees and non-financial support from Eli Lilly, personal fees and non-financial support from Novo Nordisk, grants and personal fees from Boehringer Ingelheim, grants, personal fees and non-financial support from Medtronic, personal fees and non-financial support from Abbott, personal fees and non-financial support from BMS, personal fees and non-financial support from MSD, and grants, personal fees and nonfinancial support from AstraZeneca. LP reports personal fees and nonfinancial support from Sanofi, personal fees and non-financial support from Eli Lilly, personal fees and non-financial support from Novo Nordisk, and personal fees and non-financial support from MSD. RR reports grants, personal fees and non-financial support from Sanofi, grants, personal fees and non-financial support from Novo Nordisk, personal fees and non-financial support from Eli Lilly, personal fees from Mundipharma, personal fees from Janssen, personal fees from Servier, grants and personal fees from AstraZeneca, personal fees from MSD, personal fees from Medtronic, personal fees from Abbott, grants from Diabnext, and personal fees from Applied Therapeutics. JFG reports personal fees and non-financial support from Eli Lilly, personal fees and non-financial support from Novo Nordisk, personal fees and nonfinancial support from Gilead, and personal fees and non-financial support from AstraZeneca. PG reports personal fees from Abbott, personal fees from Amgen, personal fees from AstraZeneca, personal fees from Boehringer Ingelheim, personal fees from Eli Lilly, personal fees from MSD, personal fees from Mundipharma, grants and personal fees from Novo Nordisk, personal fees from Sanofi, and personal fees from Servier. All other authors declare that there are no relationships or activities that might bias, or be perceived to bias, their work.

Contribution statement $\mathrm{BC}, \mathrm{SH}$ and $\mathrm{MW}$ had full access to all of the data in the study and take responsibility for the integrity of the data and the accuracy of the data analysis. BC, SH and MW contributed to the work equally and should be regarded as co-first authors. Concept and design: BC, JFG, PG, SH, MP, RRoussel, MW. Acquisition, analysis, or interpretation of data: BB, DB, BC, FC-R, CC, J-FG, PG, SH, VK, BL, MP, RRobert, RRoussel, J-FT, CT, MW on behalf of the scientific committee of the study (the list of scientific committee is available in the ESM). Statistical analysis: MW, SC, PJS. Patient recruitment: AA-S, IA, CA, GA, FB, SB, MB-G, OB, BC, EC, PD, ED, AD-B, BG, J-FG, PG, SH, MJ, VK, LMarchand, LMeyer, LP, GP, J-PR, RRoussel, AS, CT, BT, CV. Fundraising: BC, PG, SH, MP and BB. Drafting the manuscript: BC, $\mathrm{PG}, \mathrm{SH}, \mathrm{MP}, \mathrm{MW}$. Critical revision of the manuscript for important intellectual content: all co-authors. All authors have approved the final version of the manuscript.

Open Access This article is licensed under a Creative Commons Attribution 4.0 International License, which permits use, sharing, adaptation, distribution and reproduction in any medium or format, as long as you give appropriate credit to the original author(s) and the source, provide a link to the Creative Commons licence, and indicate if changes were made. The images or other third party material in this article are included in the article's Creative Commons licence, unless indicated otherwise in a credit line to the material. If material is not included in 
the article's Creative Commons licence and your intended use is not permitted by statutory regulation or exceeds the permitted use, you will need to obtain permission directly from the copyright holder. To view a copy of this licence, visit http://creativecommons.org/licenses/by/4.0/.

\section{References}

1. Huang C, Wang Y, Li X et al (2020) Clinical features of patients infected with 2019 novel coronavirus in Wuhan, China. Lancet 395(10223):497-506. https://doi.org/10.1016/S0140-6736(20) 30183-5

2. Guan WJ, Ni ZY, Hu Y et al (2020) Clinical characteristics of coronavirus disease 2019 in China. N Engl J Med 382(18):17081720. https://doi.org/10.1056/NEJMoa2002032

3. Shah BR, Hux JE (2003) Quantifying the risk of infectious diseases for people with diabetes. Diabetes Care 26(2):510-513. https://doi. org/10.2337/diacare.26.2.510

4. Muller LM, Gorter KJ, Hak E et al (2005) Increased risk of common infections in patients with type 1 and type 2 diabetes mellitus. Clin Infect Dis 41(3):281-288. https://doi.org/10.1086/ 431587

5. Yang JK, Feng Y, Yuan MY (2006) Plasma glucose levels and diabetes are independent predictors for mortality and morbidity in patients with SARS. Diabet Med 23(6):623-628. https://doi.org/10. 1111/j.1464-5491.2006.01861.x

6. Alqahtani FY, Aleanizy FS, Ali El Hadi Mohamed R et al (2018) Prevalence of comorbidities in cases of Middle East respiratory syndrome coronavirus: a retrospective study. Epidemiol Infect 147:1-5. https://doi.org/10.1017/S0950268818002923

7. Yang J, Zheng Y, Gou X et al (2020) Prevalence of comorbidities in the novel Wuhan coronavirus (COVID-19) infection: a systematic review and meta-analysis. Int J Infect Dis 94:91-95. https://doi.org/ 10.1016/j.ijid.2020.03.01

8. Grasselli G, Zangrillo A, Zanella A et al (2020) Baseline characteristics and outcome of 1591 patients infected with SARS-CoV-2 admitted to ICUs of the Lombardy region, Italy. JAMA 323(16): 1674-1581. https://doi.org/10.1001/jama.2020.5394

9. Garg S, Kim L, Whitaker M et al (2020) Hospitalization rates and characteristics of patients hospitalized with laboratory-confirmed coronavirus disease 2019 - COVID-NET, 14 States, March 1-30, 2020. MMWR Morb Mortal Wkly Rep 69(15):458-464. https:// doi.org/10.15585/mmwr.mm6915e3

10. Onder G, Rezza G, Brusaferro S (2020) Case-fatality rate and characteristics of patients dying in relation to COVID-19 in Italy. JAMA. https://doi.org/10.1001/jama.2020.4683

11. Bhatraju PK, Ghassemieh BJ, Nichols M et al (2020) Covid-19 in critically ill patients in the Seattle region - case series. N Engl J Med. https://doi.org/10.1056/NEJMoa2004500

12. Zhou F, Yu T, Du R et al (2020) Clinical course and risk factors for mortality of adult inpatients with COVID-19 in Wuhan, China: a retrospective cohort study. Lancet 395(10229):1054-1062. https:// doi.org/10.1016/S0140-6736(20)305

13. Wu C, Chen X, Cai Y et al (2020) Risk factors associated with acute respiratory distress syndrome and death in patients with coronavirus disease 2019 pneumonia in Wuhan, China. JAMA Intern Med. https://doi.org/10.1001/jamainternmed.2020.0994

14. Roncon L, Zuin M, Rigatelli G, Zuliani G (2020) Diabetic patients with COVID-19 infection are at higher risk of ICU admission and poor short-term outcome. J Clin Virol 127:104354. https://doi.org/ 10.1016/j.jcv.2020.104354
15. Centers for Disease Control and Prevention (2020) Coronavirus Disease 2019 (COVID-19): groups at higher risk for severe illness. Available from https://aimvein.com/blogs/news/covid-19-measurefor-high-risk-groups. Accessed 21 April 2020

16. Sauerbrei W, Meier-Hirmer C, Benner A, Royston P (2006) Multivariable regression model building by using fractional polynomials: description of SAS, STATA and R programs. Comput Stat Data Anal 50(12):3464-3485. https://doi.org/10.1016/j.csda. 2005.07.015

17. Pornet C, Bourdel-Marchasson I, Lecomte P et al (2011) Trends in the quality of care for elderly people with type 2 diabetes: the need for improvements in safety and quality (the 2001 and 2007 ENTRED Surveys). Diabetes Metab 37(2):152-161. https://doi. org/10.1016/j.diabet.2011.02.001

18. Yang X, Yu Y, Xu J et al (2020) Clinical course and outcomes of critically ill patients with SARS-CoV2 pneumonia in Wuhan, China: a single-centered, retrospective, observational study. Lancet Respir Med 8(5):475-481. https://doi.org/10.1016/S22132600(20)30079-5

19. CDC COVID-19 response team (2020) Preliminary estimates of the prevalence of selected underlying health conditions among patients with coronavirus disease 2019 - United States, February 12March 28, 2020. MMWR Morb Mortal Wkly Rep 69(13):382386. https://doi.org/10.15585/mmwr.mm6913

20. Huang I, Anthonius M, Pranata R (2020) Diabetes mellitus is associated with increased mortality and severity of disease in COVID19 pneumonia - a systematic review, meta-analysis, and metaregression. Diabetes Metab Syndr 14(4):395-403. https://doi.org/ 10.1016/j.dsx.2020.04.018

21. Kulcsar J, Coleman CM, Beck SE, Frieman MD (2019) Comorbid diabetes results in immune dysregulation and enhanced disease severity following MERS-CoV infection. JCI Insight 4(20): e131774. https://doi.org/10.1172/jci.insight.13177

22. Simonnet A, Chetboun M, Poissy J et al (2020) High prevalence of obesity in severe acute respiratory syndrome coronavirus-2 (SARS$\mathrm{CoV}-2$ ) requiring invasive mechanical ventilation. Obesity (Silver Spring). https://doi.org/10.1002/oby.22831

23. Schetz M, De Jong A, Deane AM et al (2019) Obesity in the critically ill: a narrative review. Intensive Care Med 45(6):757-769. https://doi.org/10.1007/s00134-019-05594-1

24. Vaduganathan M, Vardeny O, Michel T, McMurray JJV, Pfeffer MA, Solomon SD (2020) Renin-angiotensin-aldosterone system inhibitors in patients with COVID-19. N Engl J Med 382(17): 1653-1659. https://doi.org/10.1056/NEJMsr2005760

25. Drucker DJ (2020) Coronavirus infection and type 2 diabetes shared-pathways with therapeutic implications. Endocr Rev 41(3): bnaa011. https://doi.org/10.1210/endrev/bnaa011

26. Van den Berghe G, Wouters P, Weekers F et al (2001) Intensive insulin therapy in critically ill patients. N Engl J Med 345(19): 1359-1367. https://doi.org/10.1056/NEJMoa011300

27. Fosse-Edorh S, Mandereau-Bruno L, Piffaretti C (2018). Le poids du diabète en France en 2016 Synthèse épidémiologique. Santé publique France: $8 p$; available from https://www. santepubliquefrance.fr/maladies-et-traumatismes/diabete/ documents/rapport-synthese/le-poids-du-diabete-en-france-en2016.-synthese-epidemiologique. Accessed 21 April 2020 [Article in French]

Publisher's note Springer Nature remains neutral with regard to jurisdictional claims in published maps and institutional affiliations. 


\section{Affiliations}

\section{Bertrand Cariou ${ }^{1}$ (D) - Samy Hadjadj ${ }^{1}$ (D) $\cdot$ Matthieu Wargny ${ }^{1,2}$ (D) Matthieu Pichelin ${ }^{1}$ (D) A Abdallah Al-Salameh ${ }^{3}$ (D) Ingrid Allix ${ }^{4}$. Coralie Amadou ${ }^{5}$ (D) - Gwénaëlle Arnault ${ }^{6}$. Florence Baudoux ${ }^{7}$. Bernard Bauduceau ${ }^{8,9}$. Sophie Borot ${ }^{10}$ (D) Muriel Bourgeon-Ghittori ${ }^{11}$. Olivier Bourron ${ }^{12}$ (D) $\cdot$ David Boutoille ${ }^{13}$ (D) . France Cazenave-Roblot ${ }^{14,15}$ (D) Claude Chaumeil $^{16} \cdot$ Emmanuel Cosson $^{17,18}$ (D) Sandrine Coudol ${ }^{2}$. Patrice Darmon ${ }^{19}$ D Emmanuel Disse ${ }^{20}$ (D) Amélie Ducet-Boiffard ${ }^{21}$ - Bénédicte Gaborit $^{22}$ (D) Michael Joubert $^{23}$ (D)

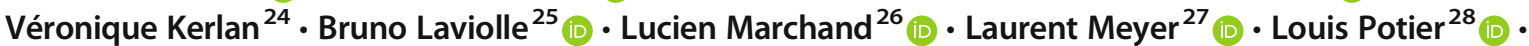 Gaëtan Prevost ${ }^{29}$ - Jean-Pierre Riveline ${ }^{30,31,32}$ (D) René Robert $^{33}$ (D) - Pierre-Jean Saulnier ${ }^{34}$ (D) Ariane Sultan $^{35}$ (D) Jean-François Thébaut ${ }^{16}$ (D) Charles Thivolet ${ }^{36,37}$ (D) Blandine Tramunt $^{38} \cdot$ Camille Vatier $^{39,40}$ (D) Ronan Roussel $^{28}$ (D) . Jean-François Gautier ${ }^{30,32}$ (D) Pierre Gourdy ${ }^{38}$ - for the CORONADO investigators}

1 Département d'Endocrinologie, Diabétologie et Nutrition, l'institut du thorax, Inserm, CNRS, UNIV Nantes, CHU Nantes, Hôpital Guillaume et René Laennec, 44093 Nantes Cedex 01, France

2 CIC-EC 1413, Clinique des Données, CHU Nantes, Nantes, France

3 Département d'Endocrinologie, Diabétologie et Nutrition, CHU Amiens, PeriToxUMR_ I 01, Université de Picardie, Amiens, France

4 Département d'Endocrinologie, Diabétologie, Nutrition, CHU de Angers, Angers, France

5 Département de Diabétologie, Centre Hospitalier Sud Francilien, Corbeil Essonne, France

6 Département d'Endocrinologie, Diabétologie et Maladies Métaboliques, Centre Hospitalier Bretagne Atlantique, Vannes, France

7 Clinique d'Endocrinologique Marc-Linquette, Hôpital ClaudeHuriez, CHRU de Lille, Lille, France

8 Département de Diabétologie, H.I.A. Begin, Saint Mandé, France

9 Fondation Francophone pour la Recherche sur le Diabète (FFRD), Paris, France

10 Département d'Endocrinologie, Diabétologie et Nutrition, CHU de Besançon, Besançon, France

11 Département d'Endocrinologie, Diabétologie et Nutrition, Assistance Publique Hôpitaux de Paris, Université Paris Saclay, Hôpital Antoine Béclère, Clamart, Hôpital Bicêtre, Le Kremlin Bicêtre, France

12 Sorbonne Université, Assistance Publique Hôpitaux de Paris, Département de Diabétologie, CHU La Pitié Salpêtrière-Charles Foix, Inserm, UMR_S 1138, Centre de Recherche des Cordeliers, Paris 06, Institute of Cardiometabolism and Nutrition ICAN, Paris, France

13 Département des Maladies Infectieuses et Tropicales, CHU Nantes, Nantes, France

14 Département des Maladies Infectieuses et Tropicales, CHU de Poitiers, INSERM U1070, Poitiers, France

15 Société de Pathologie Infectieuse de langue Française (SPILF), Paris, France

16 Fédération Française des Diabétiques (FFD), Paris, France
17 Assistance Publique Hôpitaux de Paris, Hôpital Avicenne, Université Paris 13, Sorbonne Paris Cité, Département d'Endocrinologie, Diabétologie et Nutrition, CRNH-IdF, CINFO, Bobigny, France

18 Université Paris 13, Sorbonne Paris Cité, UMR U557 Inserm / U11125 INRAE / CNAM / Université Paris13, Unité de Recherche Epidémiologique Nutritionnelle, Bobigny, France

19 Département d'Endocrinologie et de Diabétologie, Hôpital de la Conception, Assistance Publique Hôpitaux de Marseille, Marseille, France

20 Département d'Endocrinologie, Diabétologie et Nutrition, Hospices Civils de Lyon, CarMeN Laboratory, Inserm 1060, Lyon, France, Université Claude Bernard Lyon 1, Lyon, France

21 Département d'Endocrinologie et de Diabétologie, Centre Hospitalier Départemental de Vendée, La Roche sur Yon, France

22 Département d'Endocrinologie et de Diabétologie, Hôpital Nord, Assistance Publique Hôpitaux de Marseille, Marseille, France

23 Département de Diabétologie, CHU de Caen, Caen, France

24 Département d'Endocrinologie, CHU de Brest, EA 3878 GETBO, Brest, France

25 Université de Rennes, CHU Rennes, Inserm, CIC 1414 (Centre d'Investigation Clinique de Rennes), Rennes, France

26 Département d'Endocrinologie et de Diabétologie, Centre Hospitalier St. Joseph - St. Luc, Lyon, France

27 Département d'Endocrinologie, Diabétologie et Nutrition, Hôpitaux Universitaires de Strasbourg, Strasbourg, France

28 Département d'Endocrinologie, Diabétologie et Nutrition, Hôpital Bichat, Assistance Publique Hôpitaux de Paris, Centre de Recherche des Cordeliers, Inserm, U-1138, Université de Paris, Paris, France

29 Département d'Endocrinologie, Diabétologie et Maladies Métaboliques, CHU de Rouen, Université de Rouen, Rouen, France

30 Département Diabète et Endocrinologie, Hôpital Lariboisière, Assistance Publique Hôpitaux de Paris, Paris, France

31 Paris Diderot-Paris VII Université, Paris, France 
32 Inserm UMRS 1138, Université Paris Diderot-Paris VII, Sorbonne Paris Cité, Paris, France

33 Université de Poitiers, CIC Inserm 1402, Poitiers, Médecine Intensive Réanimation, Poitiers, France

34 Centre d'Investigation Clinique CIC 1402, Université de Poitiers, Inserm, CHU de Poitiers, Poitiers, France

35 Département d'Endocrinologie, Diabète, Nutrition et CIC Inserm 1411, CHU de Montpellier, Montpellier, France

36 Centre du Diabète DIAB-eCARE, Hospices Civils de Lyon et Laboratoire CarMeN, Inserm, INRA, INSA, Université Claude Bernard Lyon 1, Lyon, France
37 Société Francophone du Diabète (SFD), Paris, France

38 Département d'Endocrinologie, Diabétologie et Nutrition, CHU Toulouse, Institut des Maladies Métaboliques et Cardiovasculaires, UMR1048 Inserm/UPS, Université de Toulouse, Toulouse, France

39 Assistance Publique Hôpitaux de Paris, Saint-Antoine Hospital, Reference Center of Rare Diseases of Insulin Secretion and Insulin Sensitivity (PRISIS), Department of Endocrinology, Paris, France

40 Sorbonne University, Inserm UMRS 938, Saint-Antoine Research Center, Paris, France 